\title{
Maternal and fetal parameters in pregnant woman undergoing tocolysis with nifedipine
}

\author{
Alex Sandro Rolland Souza 1 \\ iD https://orcid.org/0000-0001-7039-2052 \\ Gabriela Correia Wanderley 2 \\ iD https://orcid.org/0000-0001-6649-1381 \\ Maria Eduarda Vilanova da Costa Pereira 3 \\ https://orcid.org/0000-0002-0270-7013 \\ Marcela Rezende Franco 4 \\ https://orcid.org/0000-0002-1741-5945
}

\author{
Débora lalle Pessoa de Sousa 5 \\ iD https://orcid.org/0000-0003-0788-5932 \\ Ellen Caroline da Silva Girão 6 \\ D https://orcid.org/0000-0002-2309-4199 \\ Gustavo Fonseca de Albuquerque Souza 7 \\ iD https://orcid.org/0000-0002-1794-701X \\ Gláucia Virgínia de Queiroz Lins Guerra 8 \\ (iD) https://orcid.org/0000-0001-6110-678X
}

\footnotetext{
${ }^{1}$ Centro de Atenção à Mulher. Instituto de Medicina Integral Prof. Fernando Figueira. Rua dos Coelhos, 300. Boa Vista. Recife, PE, Brasil. CEP. 50.070-550. E-mail: alexrolland@uol.com.b

2,3,4 Faculdade Pernambucana de Saúde. Recife, PE, Brasil.

5,6,7 Universidade Católica de Pernambuco. Recife, PE, Brasil.

8 Residência Médica em Ginecologia e Obstetrícia. Instituto de Medicina Integral Prof. Fernando Figueira. Recife, PE, Brasil.
}

\begin{abstract}
Objectives: to evaluate the effects of nifedipine with tocolysis under maternal and fetal parameters.

Methods: a cohort study with 40 pregnant women admitted at a high-risk pregnancy ward to inhibit premature labor between September/2010 to May/2012. Nifedipine was used as a $20 \mathrm{mg}$ sublingual attack dose and maintained $20 \mathrm{mg}$ every six and eight hours orally. The variables of the analysis were fetal heart rate (FHR), maternal heart rate (MHR), systolic blood pressure $(S B P)$ and diastolic blood pressure (DBP), and amniotic fluid index (AFI). All the variables were evaluated prior to administrating nifedipine and approximately after 6 hours and every 24 hours, until hospital discharge.

Results: there were no modification of the FHR $(p=0.48)$ and the SBP $(p=0.29)$. The MHR increased after 24 hours, but with no statistical difference $(p=0.08)$, returning to similar levels as at admission within 48 hours. The DBP decreased at $6(p=0.04)$ to 72 hours, being stable afterwards. The AFI decreased significantly at 24, 48 and 72 hours.

Conclusions: the use of high doses of nifedipine with tocolysis causes a decrease of the maternal's diastolic blood pressure and consequently decreases the amniotic fluid index, but probably without any clinical repercussions.
\end{abstract}

Key words Tocolysis, Nifedipine, Amniotic fluid index, Premature labor, Prenatal ultrasonography 


\section{Introduction}

Premature childbirth (PCB) is defined as a pregnancy termination of until the $37^{\text {th }}$ week or 259 days, counting from the first day of the last menstrual period. ${ }^{1}$ This is an important cause for perinatal morbidity and mortality and, therefore, a worldwide public health problem, since approximately 15 million premature childbirths occur and are responsible for almost 1 million newborns' deaths per year. 2,3

The cervix measurement by transvaginal ultrasonography, the use of vaginal progesterone in patients at risk and tocolytic therapy in symptomatic patients are interventions in preventing and avoiding premature childbirth incidence.4-8 Several tocolytic agents have already been researched.4-6 The most used drug for this purpose is nifedipine, which is effective and of low cost. 6

Nifedipine is a dihydropyridine blocker with low toxicity and teratogenicity which blocks the extracellular calcium influx into the myometrial cell membrane, as well as interacting with intracellular calcium fixed proteins.9-11 This action leads to the relaxation of soft muscles, mainly vascular, uterine and bladder.9-11 The drug has a vasomotor action, maternal and fetal, and a coronary and peripheral vasodilator effect. ${ }^{9,10}$ Thus, a decrease in the blood pressure is observed in hypertensive pregnant women which is controversial in normotensive.9-13

Maternal side effects of nifedipine are well described, and may occur due to the peripheral vasodilator effect.4,5 However, fetal adverse effects are little known, 10-13 despite crossing the placental barrier and being presented in the amniotic fluid. 14 Studies on animals suggest that calcium channel blockers may decrease uteroplacental flow. 9,10 However, studies on humans have not confirmed any significant alterations, but there are controversial results. $6,11,12,15-17$

The amniotic fluid plays an important role in the fetal development. Its production is influenced by the uteroplacental flow, which can cause oligohydramnios, in case it decreases. 18 However, no studies have been found on the effect of nifedipine on the volume of the amniotic fluid. Thus, using an ultrasonography to measure the amniotic fluid index (AFI), our objective was to determine the AFI in pregnant women with premature labor who underwent tocolysis with nifedipine, in addition to systolic blood pressure (SBP) and diastolic blood pressure (DBP) and maternal heart rate (MHR) and fetal heart rate (FHR).

\section{Methods}

A prospective observational cohort study was conducted at the Centro de Atenção a Mulher (CAM) (Woman's Care Center) at the Instituto de Medicina Integral Prof. Fernando Figueira (IMIP), with 40 pregnant women using nifedipine to inhibit a threat or premature labor from September, 2010 to May, 2012.

The sample size was calculated using OpenEpi 2.3.1 program (Atlanta, GA, USA), considering data from an analysis carried out with the first 10 patients. For a AFI mean before and after using nifedipine of $13.0 \pm 4.0 \mathrm{~cm}$ and $9.0 \pm 4.0 \mathrm{~cm}$, respectively, at a $95 \%$ confidence level and $80 \%$ of probability, 32 patients would be needed, but the number increased to 40 pregnant women.

The inclusion criteria were: singleton, topical and alive fetus; gestational age from 26 to 35 weeks; intact amniotic membrane; threat diagnosic or premature labor using nifedipine. Pregnant women with chorioamnionitis, significant uterine fibroids, fetal malformation and the use of other tocolytics were excluded.

The frequency of uterine contractions in one hour and cervical evaluation were subjectively assessed in the obstetric emergency room by an assistant physician on duty through a perception of a manual and the indicatation of tocolysis, when considered relevant, without any interference from the researchers.

Premature labor was defined as persistent uterine contractions (four in 20 minutes or eight in 60 minutes) with cervical alterations $(80 \%$ of effacement or cervical dilation of $>2 \mathrm{~cm}$ ). 19 The threat of premature labor was characterized by an increase in the uterine contractile pattern for the gestational age and the absence of the cervical modifications. 19

The variables for characterizing the sample were: maternal age; gestational age; number of previous pregnancies, including current one; parity; cervical dilation; number of uterine contractions in 20 minutes; total dose of nifedipine; frequency of threat or premature labor; working without any income; total time using nifedipine; and currently a family income of $<1$ minimum wage. The variables of analysis were: AFI (cm), SBP $(\mathrm{mmHg})$ and DBP $(\mathrm{mmHg})$ and MHR (bpm) and FHR (bpm).

After the solicitated prescription requested by the assistant physician, nifedipine was administered, according to the service protocol, 20 sublingually, attacking dose of $20 \mathrm{mg}$, repeated after 30 minutes, if needed (maximum of three doses), and maintaining $20 \mathrm{mg}$ orally at every 6 hours in the first 24 hours and 
every 8 hours in the subsequent 24 hours.

The SBP, DBP and MHR were measured by the researcher, once, at the time of the ultrasonography, using a professional adult stestoscope (WelchAllyn), hand-held anaeroid sphygmomanometer (WelchAllyn, Tycos Classic) and finger oximeter (GTech, OledGraph), calibrated and used exclusively for the research. For SBP, the $1^{\text {st }}$ Korotkoff noise was considered and for DBP, the $5^{\text {th }}$ noise was considered.

The ultrassonography was performed by medical specialists in the Medicina Fetal do CAM-IMIP (Fetal Medicine Sector), measuring the FHR and the AFI and using na equipment (Toshiba SSA - 350th, Corevision) with triplex system and convex transducer of $3.75 \mathrm{MHz}$. The FHR was measured once, while the AFI was measured three times, considered being the average to be analyzed.

All the assessments (SBP, DBP, MHR, FHR and AFI) were performed at the patient's admission and at every 6 hours in 24 hours using nifedipine, until hospital discharge or at childbirth, without any prior knowledge of previous measurements and performed by different evaluators.

To measure the AFI, the maternal abdomen was divided into four quadrants, using two perpendicular imaginary lines that intersect at the level of the umbilical scar. The vertical diameter of the largest pocket of the amniotic fluid in each quadrant in centimeters was measured and the sum of the values determined the index. 18

Data collection started after the approval of the project by IMIP Human Research Ethics Committee (document number 1656-10), CAAE 0181.0.099.000-09, the patient was only included after agreeing and signing the Informed Consent Form.

The statistical analysis was performed using software R version 3.5.1 (Vienna, Austria). The data were summarized by means and the standard deviations on the five occasions, and a mixed linear regression model was adjusted. The multiple comparisons of means were performed by Student $t$ test, with adjustment for multiple testing by Benjamini \& Hochberg's method and confidence intervals obtained at $95 \%$ (CI95\%) for the mean difference between each pair of occasions. For all the analyzes, $p<0.05$ was considered.

\section{Results}

53 pregnant women with a diagnosis of threat or premature labor were contacted, 11 of whom did not meet the inclusion criteria. Of the 42 eligible women, one was excluded due to chorioamnionitis and uterine fibroids, totaling 40 pregnant women with 149 assessments (Baseline: 40; 6 hours: 38; 24 hours: 34; 48 hours: 27 and 72 hours: 10).

Maternal age ranged from 14 to 36 years, with a mean of $22.2 \pm 6.5$ years. The mean of the gestational age was $31.2 \pm 1.9$ weeks, ranging from 26 to 34 weeks. Most of the pregnant women had premature labor $(92.5 \%)$ and had no monetary income $(85 \%), 35 \%$ had a family income of $<1$ minimum wage. The median cervical dilation at admission was $3.0 \mathrm{~cm}$ and the number of uterine contractions in 20 minutes was four. The average total dose of nifedipine was $202.5 \mathrm{mg}$ and the duration of use was three days.

In Table 1 shows the sample and estimated means, the standard deviation and CI95\% of the FHR, MHR, SBP, DBP and AFI, before nifedipine and at $6,24,48$ and 72 hours.

In Figure 1 shows that there were significant differences in the estimated means of MHR $(p=0.03)$, DBP $(p<0.001)$ and AFI $(p<0.001)$.

The estimated mean of the FHR remained unchanged in the assessments $(p=0.48)$ (Table 2; Figure 1).

It was emphasized that the FHR increased from 86.0 to $91.7 \mathrm{bpm}$ after 24 hours, without any statistical significance $(p=0.08)$, and began to decrease, returning to the baseline value after 48 hours (Tables 1 and 2; Figure 1).

The estimated mean of SBP did not alter significantly ( $p=0.29$ ) (Table 2; Figure 1). Meanwhile, the estimated mean of DBP decreased significantly from 6 hours ( $p=0.04$ ) to 72 hours ( $p=0.04$ ), presenting a great decrease within 24 hours, from 69.0 to 61.3 $\mathrm{mmHg}(p<0.001)$, compared to the baseline values. It is noteworthy that when comparing the estimated means of DBP between the hours, there were no significant differences observed (Table 2; Figure 1).

The estimated mean of the AFI did not alter significantly within 6 hours $(p=0.13)$, but decreased from 13.6 to $10.9 \mathrm{~cm}$ after 24 hours $(p<0.001)$, to $10.0 \mathrm{~cm}$ after 48 hours $(p<0.001)$ and for $8.6 \mathrm{~cm}$ within 72 hours $(p<0.001)$, compared to the baseline values (Tables 1 and 2). There was a significant difference from the estimated mean within the 6 hours of nifedipine use compared to 24 hours $(p<0.001)$, in 48 hours $(p<0.001)$ and in 72 hours $(p<0.001)$, and in addition to 24 hours compared to 72 hours $(p=0.02)$ (Table 2; Figure 1). 
Table 1

Mean and standard deviation (SD) of the sample and estimated means and $95 \%$ confidence interval (CI95\%) of the maternal heart rate (MHR), fetal heart rate (FHR), systolic blood pressure (SBP), diastolic blood pressure (DBP) and amniotic fluid index (AFI) of pregnant women who underwent tocolysis with nifedipine.

\begin{tabular}{|c|c|c|c|c|c|}
\hline Variables & Baseline $(n=40)$ & $6 h(n=38)$ & $24 h(n=34)$ & $48 h(n=27)$ & $72 h(n=10)$ \\
\hline FHR (bpm): Mean sample (SD) & $143.6(8.2)$ & $146.4(10.5)$ & $144.5(11.8)$ & $141.3(22.6)$ & $142.2(9.7)$ \\
\hline Estimated means (CI95\%) & $143.6(139.5-147.7)$ & $146.4(142.2-150.6)$ & $144.5(140.0-148.9)$ & $141.3(136.4-146.2)$ & $141.6(133.5-149.7)$ \\
\hline MHR (bpm): Mean sample (SD) & $86.0(12.5)$ & $90.0(14.2)$ & $91.6(13.9)$ & $84.8(10.6)$ & $80.8(9.6)$ \\
\hline Estimated means ( $\mathrm{Cl} 95 \%)$ & $86.0(82.0-90.1)$ & $90.1(86.0-94.2)$ & $91.7(87.4-95.9)$ & $85.7(81.0-90.3)$ & $85.3(78.3-92.2)$ \\
\hline SBP $(\mathrm{mmHg})$ : Mean sample (SD) & $110.4(12.3)$ & $107.2(11.3)$ & $107.2(12.9)$ & $107.6(12.5)$ & $105.0(5.3)$ \\
\hline Estimated means ( $\mathrm{Cl} 95 \%)$ & $110.4(106.7-114.1)$ & $106.9(103.2-110.7)$ & $107.0(103.1-110.9)$ & $107.6(103.4-111.7)$ & $107.7(101.7-113.6)$ \\
\hline DBP $(\mathrm{mmHg})$ : Mean sample (SD) & $69.0(10 . .3)$ & $65.0(9.9)$ & $61.5(9.6)$ & $62.8(11.5)$ & $62.5(7.9)$ \\
\hline Estimated means ( $\mathrm{Cl} 95 \%)$ & $69.0(659-72.1)$ & $65.0(61.8-68.1)$ & $61.3(58.0-64.6)$ & $62.6(59.1-66.1)$ & $62.9(57.8-68.0)$ \\
\hline AFI (cm): Mean sample (SD) & $13.6(3.6)$ & $13.1(4.0)$ & $10.8(4.0)$ & $9.9(3.6)$ & $6.3(3.5)$ \\
\hline Estimated means ( $\mathrm{Cl} 95 \%)$ & $13.6(12.4-14.8)$ & $12.9(11.7-14.2)$ & $10.9(9.7-12.1)$ & $10.0(8.8-11.3)$ & $8.6(7.0-10.2)$ \\
\hline
\end{tabular}

$\mathrm{FHR}=$ fetal heart rate; $\mathrm{MHR}=$ matenal heart rate; SBP = maternal systolic blood pressure; $\mathrm{DBP}=\mathrm{maternal}$ diastolic blood pressure; $\mathrm{AFI}=$ amniotic fluid index after tocolysis with nifedipine; bpm = beats per minute; $\mathrm{cm}$ : centimeters; $\mathrm{mmHg}=\mathrm{millimeters}$ of mercury; $\mathrm{SD}=$ standard deviation; $\mathrm{Cl}=$ confidence interval.

Figure 1

The estimated means and the $95 \%$ confidence interval of the maternal heart rate, fetal heart rate, systolic blood pressure, diastolic blood pressure and the amniotic fluid index of pregnant women who underwent tocolysis with nifedipine.
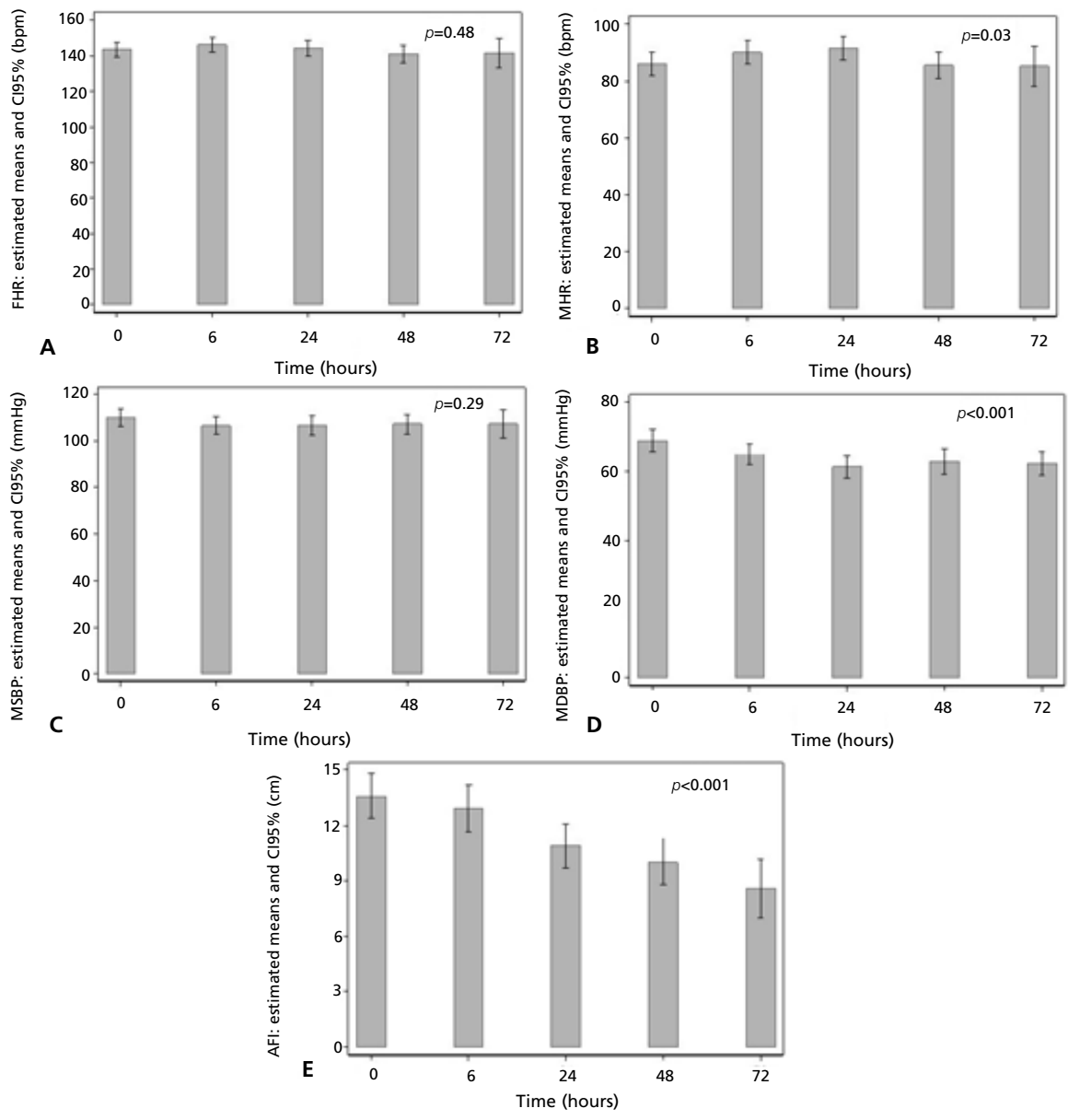

A) $\mathrm{FHR}=$ fetal heart ratet; $\mathrm{B}) \mathrm{MHR}=$ maternal heart rate; $\mathrm{C}) \mathrm{SBP}=$ maternal systolic blood pressure; $\mathrm{D}) \mathrm{DBP} *=\mathrm{maternal}$ diastolic blood pressure; $\mathrm{E}$ ) $\mathrm{AFI}^{*}=$ amniotic fluid index. * $p<0.05$ (mixed linear regression model). 
Adjusted multiple comparisons between the estimated means of fetal heart rates (FHR), maternal heart rate (MHR), systolic blood pressure (SBP) and diastolic blood pressure (DBP) and the amniotic fluid index (AFI) after tocolysis with nifedipine.

\begin{tabular}{|c|c|c|c|c|c|c|c|c|c|c|}
\hline & $0-6 h$ & $0-24 h$ & $0-48 \mathrm{~h}$ & $0-72 h$ & $6 h-24 h$ & $6 h-48 h$ & $6 h-72 h$ & $24 h-48 h$ & $24 h-72 h$ & $48 h-72 h$ \\
\hline \multicolumn{11}{|l|}{ FHR (bpm) } \\
\hline$\Delta$ of es timated means & -2.8 & -0.8 & 2.3 & 2.0 & 1.9 & 5.1 & 4.8 & 3.1 & 2.9 & -0.3 \\
\hline $\mathrm{Cl} 95 \%$ & $-8.4-2.8$ & $-6.6-4.9$ & $-3.8-8.4$ & $-6.9-10.9$ & $-3.9-7.8$ & $-1.1-11.2$ & $-4.2-13.7$ & $-3.2-9.5$ & $-6.2-11.9$ & $-9.5-8.9$ \\
\hline$p^{*}$ & 0.72 & 0.57 & 0.56 & 0.79 & 0.36 & 0.81 & 0.63 & 0.27 & 0.92 & 0.53 \\
\hline \multicolumn{11}{|l|}{ MHR (bpm) } \\
\hline$\Delta$ of es timated means & -4.0 & -5.6 & 0.3 & 0.8 & -1.6 & 4.4 & 4.8 & 6.0 & 6.4 & 0.4 \\
\hline $\mathrm{Cl} 95 \%$ & $-8.3-0.2$ & $-101-1.2$ & $-4.4-5.1$ & $-6.2-7.8$ & $-6.1-2.9$ & $-0.4-9.2$ & $-2.3-11.9$ & $1.1-10.9$ & $-0.7-13.5$ & $-6.8-7.7$ \\
\hline$p^{*}$ & 0.15 & 0.08 & 0.91 & 0.91 & 0.68 & 0.15 & 0.30 & 0.08 & 0.15 & 0.91 \\
\hline \multicolumn{11}{|l|}{$\mathrm{SBP}(\mathrm{mmHg})$} \\
\hline$\Delta$ of es timated means & 3.4 & 3.4 & 2.8 & 2.7 & -0.1 & -0.6 & -0.7 & -0.5 & -0.7 & -0.1 \\
\hline $\mathrm{Cl} 95 \%$ & -0.1 to -6.9 & $-0.3-7.0$ & $-1.1-6.8$ & $-3.1-8.5$ & $-3.8-3.6$ & $-4.6-3.4$ & $-6.6-5.1$ & $-4.6-3.5$ & $-6.5-5.2$ & $-6.1-5.8$ \\
\hline$p^{*}$ & 0.64 & 0.49 & 0.23 & 0.69 & 0.10 & 0.61 & 0.89 & 0.61 & 0.36 & 0.64 \\
\hline \multicolumn{11}{|l|}{$\mathrm{DBP}(\mathrm{mmHg})$} \\
\hline$\Delta$ of es timated means & 4.0 & 7.7 & 6,4 & 6.1 & 3.7 & 2.4 & 2.1 & -1.3 & -1.6 & -0.3 \\
\hline $\mathrm{Cl} 95 \%$ & $0.9-7.1$ & $4.5-10.9$ & $3.0-9.9$ & $1.0-11.2$ & $0.5-6.9$ & $-1.1-5.9$ & $-3.1-7.2$ & $-4.8-2.3$ & $-6.8-3.5$ & $-5.6-4.9$ \\
\hline$p^{*}$ & 0.04 & $<0.001$ & 0.002 & 0.04 & 0.05 & 0.29 & 0.59 & 0.59 & 0.59 & 0.90 \\
\hline \multicolumn{11}{|l|}{$\mathrm{AFI}(\mathrm{cm})$} \\
\hline$\Delta$ of es timated means & 0.7 & 2.7 & 3.6 & 5.0 & 2.1 & 2.9 & 4.4 & 0.8 & 2.3 & 1.5 \\
\hline $\mathrm{Cl} 95 \%$ & $-0.2-1.5$ & $1.8-3.6$ & $2.6-4.5$ & $3.7-6.4$ & $1.1-3.0$ & $1.9-3.9$ & $3.0-5.8$ & $-0.1-1.8$ & $0.9-3.7$ & $0.1-2.9$ \\
\hline$p^{*}$ & 0.13 & $<0.0001$ & $<0.0001$ & $<0.0001$ & $<0.0001$ & $<0.0001$ & $<0.0001$ & 0.10 & 0.02 & 0.05 \\
\hline
\end{tabular}

$\mathrm{FHR}=$ fetal heart rate; $\mathrm{MHR}=$ maternal heart rate; $\mathrm{SBP}=$ maternal systolic blood pressure; DBP = maternal diastolic blood pressure; $\mathrm{AFI}=$ amniotic fluid index; $\mathrm{bpm}=$ beats per minute; $\mathrm{cm}=$ centimeters; $\mathrm{mmHg}=$ millimeters of mercury; $p=$ level of significance. * Student's $\mathrm{t}$ test.

\section{Discussion}

In this study, it was observed that the use of nifedipine to inhibit premature labor causes a decrease in the maternal diastolic blood pressure levels and consequently a decrease in the AFI, but probably with few clinical repercussions, as the differences were minimal. It is noteworthy that the reduction in the AFI was significant from 24 to 72 hours, being associated with a decrease in the maternal diastolic blood pressure, which began to decrease after 6 hours.

Studies suggest that a reduction in the blood pressure may occur in normotensive pregnant women who underwent tocolysis with nifedipine, however, often without any symptoms or clinical repercussions. 21,22 There is a report on a patient using nifedipine, who developed a severe hypotension. 13 While, other studies have not shown a decrease in the blood pressure levels, 12,23,24 which may be due to a wide methodological variety and of doses used. In our sample, a significant decrease in the maternal diastolic blood pressure was found after 6 hours of the first dose of nifedipine, remaining constantly up to 72 hours, this is similar to another study that was carried out with 28 pregnant women. 16 This response may be related to a decrease in uteroplacental perfusion, which may justify a reduction in the fetal diuresis, and consequently in the AFI, this was also observed in our results.

It is known that the main mechanisms of homeostasis of the amniotic fluid after the $20^{\text {th }}$ week of gestation are the perfusion of the fetal face of the placenta, the respiratory system of the fetus, the umbilical cord, diuresis and fetal swallowing. The latter two have a greater influence on the regulation of this liquid on the third quarter. Most of these mechanisms, theoretically, could be altered by a decrease in the fetal perfusion, resulting from a decrease in the maternal blood pressure. ${ }^{25}$

A systematic review of the Cochrane library suggests the use of the largest pocket measurement to assess the volume of the amniotic fluid is better for the AFI, as it performs diagnoses of oligoamnium and makes pregnant women to induce labor in lower frequencies, but without any significant difference in terms of perinatal outcomes. ${ }^{26}$ Despite the review, we opted, in the present study, to use AFI because it presents excellent reproducibility and an insignificant difference between and within the inter- 
observer. ${ }^{25,27}$ As our objective was not to determine the frequency of the alterations in the volume of the amniotic fluid and its outcomes, however the evolution of its measurement was important, 25 the chosen technique was the AFI.

In the researched literature, no study was found that assessed the amniotic fluid in pregnant women undergoing tocolysis with nifedipine. Our study found a decrease in the volume of the amniotic fluid after 24 hours of using nifedipine, which was maintained after 72 hours. This decrease in volume probably occurred due to a decrease in the blood pressure and / or a decrease in uteroplacental flow. 17 The effects of nifedipine described in the literature in another population, is controversial, in normotensive pregnant women. 21

Several studies have addressed the effects of nifedipine on the uteroplacental flow in pregnant women inhibiting labor with nifedipine, but the results are quite controversial.6,12,15-17,21,23,24,28 In a study carried out with 28 pregnant women who underwent tocolysis with nifedipine evaluated the blood flow of the umbilical, uterine and fetal middle cerebral arteries using velocimetric doppler parameters and the atrioventricular valves in the first 48 hours of therapy. It was found that after 24 hours of tocolytic treatment with nifedipine, there was a reduction in the pulsatility index in the uterine and fetal middle cerebral artery, which may influence the perfusion of the fetal side of the placenta, 16 similar to a study conducted with 49 pregnant women who underwent the same treatment. 6 This effect can be explained by the action of the drug on the vascular soft muscle of the maternal uterine and fetus cerebral arteries, with a dilation of the artery.

Other studies have not observed significant alterations in the velocimetric doppler indices of the uterine artery, but with divergent results in relation to the umbilical artery and fetal middle cerebral artery. 12,17,23 Similarly, a prospective, cohort study, which assessed the maternal-fetal circulation by dopplervelocimetry before, 5 and 24 hours after undergoing tocolysis with nifedipine in 47 pregnant women, concluded that there was no alteration in the resistance index of the uterine artery and there was a decrease in resistance in the fetal middle cerebral artery. 17

In our study, we also observed that the MHR increased significantly ( $p=0.03$ ), however, when the analysis was made between the hours, there was a tendency to increase the MHR, when compared to the baseline measurement within the 24 hours, similar to other studies found in the literature, in which no significant differences were observed, before and after the use of nifedipine for tocolysis.6,12,15-17,21,23,24,28 This may be due to the methodological differences among the studies, since none of them had any comparisons among various moments, in addition to this tendency increased the MHR may have been a compensatory response to a decrease in the blood pressure. ${ }^{21}$ It is noteworthy that our study was the only one found in the researched literature, in which there was a longer follow-up time, up to 72 hours, and multiple comparisons. However, according to cardiac physiological hemodynamics, it is to be expected that the decrease in systemic blood pressure will lead to an increase in heart rate. ${ }^{21}$

Although a study suggested the presence of nifedipine in the amniotic fluid of pregnant women undergoing tocolysis, 11 in relation to the fetal heart rate in our study, we did not observe any significant alterations, remained unaltered in all the assessments. This finding corroborates with the results of other studies already carried out.6,12,15-17,21,23,24,28

We concluded that this study with the use of high doses of nifedipine to inhibit premature labor, probably causes a decrease in the maternal blood pressure and a decrease in the amniotic fluid index, which could be justified by the reduction of uteroplacental perfusion and, consequently, of the fetal. As a result of disagreement with other studies, it is suggested to conduct further studies to monitor maternal blood pressure at the same time in which the doppler velocimetric indices pregnant women in the use of nifedipine for tocolysis.

It is important to note that this decrease in the volume of the amniotic fluid was probably for a limited time, while using nifedipine, and clinically not significant for the fetus, requiring further studies to prove these results, particularly with a larger sample size and longer period of time on the followup, including the assessment on newborn outcomes.

\section{Acknowledgements}

We would like to thank the Programa de Iniciação Científica do Conselho Nacional de Desenvolvimento Científico e Tecnológico (CNPq) (Scientific Program on the National Council for Scientific and Technological Development) and the Instituto de Medicina Integral Prof. Fernando Figueira (IMIP) 


\section{Author's contribution}

Souza ASR performed all the statistical analyzes and data handling. Souza ASR, Wanderley GC and Guerra GVQL contributed to the methodological discussions. Souza ASR, Wanderley GC, Pereira MEVC and Franco MR prepared the first version of the article. Souza ASR, Guerra GVQL, Wanderley GC, Pereira MEVC, Franco MR, Souza GFA, Sousa DLP and Girão ECS reviewed the article on several occasions. All authors approved the final version of the manuscript.

\section{References}

1. Reyes VAO, ParedesJNP, Moreira POO, Martínez MCC. Factores de riesgo y complicaciones de parto preterminoen adultas enel hospital León Becerra Camacho enelaño 2014 2015. Recimundo 2019; 3 (2): 449-66.

2. Liu L, Oza S, Hogan D, Perin J, Rudan I, Lawn JE, Cousens S, Mathers C, Black RE. Global, regional, and national causes of child mortality in $2000-13$, with projections to informpost-2015 priorities: an updated systematic analysis. Lancet. 2015; 385 (9966): 430-40.

3. Souza RT, Cecatti JG, Passini Jr. R, Tedesco RP, Lajos GJ, Nomura ML, Rehder PM, Dias TZ, Haddad SM, Pacagnella RC, Costa ML, Brazilian Multicenter Study on Preterm Birth study group. The Burden of Provider-Initiated Preterm Birth and Associated Factors: Evidence from the Brazilian Multicenter Study on Preterm Birth (EMIP). PLoSOne. 2016; 11 (2): e0148244.

4. Wagner P, Sonek J, Abele H, Sarah L, Hoopmann M, Brucker S, Wu Q, Kagan KO. Effectiveness of the contemporary treatment of preterm labor: a comparison with a historical cohort. Arch Gynecol Obstet. 2017; 296 (1): 27 34

5. Naik Gaunekar N, Raman P, Bain E, Crowther CA.Maintenance therapy with calcium channel blockers for preventing pretermbirth after threatened pretermlabour. Cochrane Database Syst Rev. 2013; 10: CD004071.

6. GüdenM, AkkurtMO, YalçınSE, CoşkunB, AkkurtI, Yavuz A,YirciB, Kandemir NO. A comparison of the effects of the most commonly used tocolytic agents on maternal and fetal blood flow. Turk J Obstet Gynecol. 2016; 13: 85-9.

7. Conde-Agudelo A, Romero R. Predictive accuracy of changes in transvaginal sonographic cervical length over time for pretermbirth: a systematic review and metaanalysis. Am J ObstetGynecol. 2015; 213 (6): 789-801.

8. Camacho CM, García SM, García MGB, Camacho CL. Progesterona vaginal combinada com nifedipino em la prevención de parto pretermino con cervix corto. Gac Med Bol. 2017; 40 (2): 8-11.

9. Ducsay CA, Thompson JS, Wu AT, Novy MJ. Effects of calcium blocker (nicardipine) tocolysis in rhesus macaques: fetal plasma concentrations and cardiorespiratory changes. Am J Obstet Gynecol. 1987; 157: 1482-6.
10. Harake B, Gilbert RD, Ashwal S, Power GG. Nifedipine: effects on fetal and maternal haemodynamics in pregnant sheep. Am J Obstet Gynecol. 1987; 157: 1003-8.

11. Silberschmidt A, Ku"hn-Velten W, Juon A, Zimmermann R, von Mandach U. Nifedipine concentration in maternal and umbilical cord blood after nifedipine gastrointestinal therapeutic system for tocolysis. BJOG. 2008; 115: 480-5.

12. Cornette J, Duvekot J, Roos-Hesselink J, Hop W, Steegers E. Maternal and fetal haemodynamic effects of nifedipine in normotensive pregnant women. BJOG. 2011; 118: 51-5.

13. Khoo F, Mathur M. Severe resistant maternal hypotension followingtocolysis with nifedipine. BMJ Case Rep. 2014; bcr2014208059.

14. Manninen AK, Juhakoski A. Nifedipine concentrations in maternal and umbilical serum, amniotic fluid, breast milk and urine of mothers and offspring. Int J Clin Pharmacol Res. 1991; 11 (5): 231-6.

15. Guclu S, Saygili U, Dogan E, Demir N, Baschat AA. The shortterm effect of nifedipine tocolysis on placental, fetal cerebral and atrioventricular Doppler waveforms. Ultrasound Obstet Gynecol. 2004; 24: 761-5.

16. Guclu S, Gol M, Saygili U, Demir N, Sezer O, Baschat AA. Nifedipine therapy for preterm labor: effects on placental, fetal cerebral and atrioventricular Doppler parameters in the first 48 hours. Ultrasound Obstet Gynecol. 2006; 27: 403-8.

17. Lima MMS, Souza ASR, Diniz C, Porto AMF, Amorim MMR, Moron AF. Doppler velocimetry of the uterine, umbilical and fetal middle cerebral arteries in pregnant women undergoing tocolysis with oral nifedipine. Ultrasound Obstet Gynecol. 2009; 34: 311-5.

18. Phelan JP, Ahn MO, Smith CV, Rutherford SE, Anderson E. Amniotic fluid index measurements during pregnancy. $\mathrm{J}$ Reprod Med. 1987; 32: 601-4.

19. Lamont RF. International Preterm Labour Council. Evidence-based labour ward guidelines for the diagnosis, management and treatment of spontaneous preterm labour. J Obstet Gynaecol. 2003; 23 (5): 469-78.

20. Santos LC, Mendonça VG, Porto AMF, Guerra GVQL, Coelho ICCAN, Katz L. Gestação de alto risco baseada em evidências. 1 ed. Rio de Janeiro: Medbook; 2011. p.574. 
21. Grin L, Laish-Farkash A, Shenhav S, Piltz X, Ganelin L, Rabinovich M, et al. Safety of nifedipine in threatened preterm labor: Investigation by three-dimensional echocardiography. Echocardiography. 2018; 35 (8): 1164-70.

22. Glock JL, Morales WJ. Efficacy and safety of nifedipine versus magnesium sulfate in the management of preterm labor: a randomized study. Am J Obstet Gynecol. 1993; 169: 960-4.

23. Ulubasoglu H, Bayar UO, Kaya C, Ungan B, The effect of nifedipine tocolysis on Doppler indices of the uterine and umbilical arteries. J Clin Ultrasound. 2015; 43 (5): 322-6.

24. Torres-Cepeda D, Reyna-Villasmil E, Mejía-Montilla J, Labarca-Acosta M, Delgado-Delgado O, Santos-Bolívar J, Reyna-Villasmil N. Doppler de lasarterias uterinas, umbilical y cerebral media fetal en embarazada con amenaza de parto pretérmino tratada con nifedipina oral. Rev Obstet Ginecol Venez. 2012; 72 (4): 221-6.
25. DertkigilMSJ, CecattiJG, Cavalcante SR, BaciukEP, Bernardo ALA. Líquido amniótico, atividade física e imersão em água na gestação. Rev Bras Saúde Matern Infant. 2005; 5 (4): 403-10.

26. Nabhan AF, Abdelmoula YA. Amniotic fluid index versus single deepest vertical pocket as a screening test for preventing adverse pregnancy outcome. Cochrane Database Syst Ver. 2008; 3: CD006593.

27. Schwartz DB, Daoud Y, Schuchter K, Freeman J, McGirr $\mathrm{K}$, Campbell S. Does the amniotic fluid index change over a short-term time interval?. Ultrasound Obstet Gynecol. 1992; $2: 325-8$

28. Baykal BÖ, Avcıŏlu SN. Comparison of effects of nifedipine and ritodrine onmaternal and fetal blood flow patterns in preterm labor. J Turk Ger Gynecol Assoc. 2015; 16 (2): $80-5$.

Received on July 24, 2019

Final version presented on December 27, 2019

Approved on January 30, 2020

\author{
ERRATA: \\ In Page 451, Where it reads: \\ "https://orcid.org/0000-0002-7784-854X" \\ Reading: \\ "https://orcid.org/0000-0002-1741-5945"
}

Rev Bras Saúde Matern Infant. (2020) 20(3): 915-915 